Article

\title{
Red Chalk Palimpsest: The Logic of Somba Landscape
}

\author{
Fabrice Noukpakou *, Ghita Barkouch, Nawri Khamallah and Renaud Pleitinx \\ Faculty of Architecture, Architectural Engineering and Urban Planning, UCLouvain, 1348 Louvain-la-Neuve, Belgium; \\ E-Mails: fabrice.noukpakou@uclouvain.be (F.N.), ghita.barkouch@uclouvain.be (G.B.), \\ nawri.khamallah@uclouvain.be (N.K.), renaud.pleitinx@uclouvain.be (R.P.)
}

* Corresponding author

Submitted: 15 January 2020 | Accepted: 26 May 2020 | Published: 30 June 2020

\begin{abstract}
This article presents the results of a study on the traditional settlement patterns of the Somba people, living in the department of Atacora, north-western Benin. Adopting a methodology based on both a generative approach and André Corboz's (1983) territory-palimpsest analogy, the study specifically questions the 'dispersed' character of the Somba habitat. Built upon two hypotheses, according to which Tatas Somba settle approximately to pre-existing Tatas and near to watercourses, this study seeks to understand the reasons and conditions of this dispersal throughout history. By cross-checking on-site inventory and geographic information system data allowing to analyse the distances between Tatas, archaeological sites and nearby watercourses, and thus revealing the permanent, the persistent, and the disappeared landscape elements, this article aims to prove that the settlement of the Tatas Somba is not determined by geometrical compositions, landmarks, or infrastructures, but rather by a combination of social, agricultural, environmental, and subsistence factors.
\end{abstract}

\section{Keywords}

Atacora; palimpsest; Somba landscape; Tatas Somba; watercourses

\section{Issue}

This article is part of the issue "Territories in Time: Mapping Palimpsest Horizons" edited by Chiara Cavalieri (UCLouvain, Belgium) and Elena Cogato Lanza (EPFL, Switzerland).

(C) 2020 by the authors; licensee Cogitatio (Lisbon, Portugal). This article is licensed under a Creative Commons Attribution 4.0 International License (CC BY).

\section{Introduction}

This article presents the results of a study on the traditional settlement patterns of the Somba people, living in the department of Atacora, north-western Benin. Adopting a generative-or syntactic-approach, combined with Corboz's 'territory-as-palimpsest' approach $(1983,1993)$, this study particularly questions the 'dispersed' character of the Somba habitat and seeks to understand the reasons and conditions of this dispersal.

In many ways, the Somba landscape resembles a palimpsest. The Somba people's modes of production, especially agriculture and earthen architecture, are characterised by their fragility and their lightness. As a result, they leave few visible and tangible traces of previous occupation and make few changes to the topography and hydraulic network, so much so that the settlement of the Tata does not seem to be dependent upon the per- manence nor the persistence of old buildings or previous infrastructure.

To understand the settlement of the Tata Somba in Benin, two hypotheses are proposed in this study. Inspired by anthropological studies on the habitat of the Tamberma people in Togo, the first hypothesis is that the Tata Somba settle near pre-existing Tatas, sometimes even on the sites of ancient ones, leading to the emergence of settlements or villages which, despite regular renewal, remain relatively permanent. The second hypothesis, suggested by the agricultural orientation of the Tata and by the water supply required for their construction, is that they settle near watercourses, thus making the hydrographic network the matrix of the Somba landscape. Based on the recent geographical maps of Benin published by the Institut Géographique National (IGN), on a geolocated inventory of Tatas Somba, counting 3,546 individuals, these two hypotheses are put to the test, us- 
ing QGIS software, through the analysis of the distances between the closest neighbors.

The temporal permanence of these two hypotheses is also tested through a complementary analysis. The location of classic Tatas Somba is compared to the location of 'hybrid' Tatas Somba that appear to be the result of an evolution observed since the 2000s (Padenou \& Pastor-Barrué, 2006). Furthermore, Tatas' location is compared to the location of 173 archaeological sites.

Without being able to draw a conclusion on whether there is a natural law or a social rule that mechanically determines the Tatas' settlement, ultimately, it remains dependent on local conditions and holds significant decision-making margins - the statistical results of this study nevertheless make it possible to confirm the existence of a 'common' spacing between the Tatas, and to affirm the existence of a preferential gap between the Tatas and the watercourses.

Furthermore, the comparison between classical and hybrid Tatas and the comparison between Tatas and archeological sites suggest, despite the impermanence of the Somba landscape, the perpetuation of ancestral settling habits.

\section{Context}

\subsection{Geography}

Located in northwest Benin, the Atacora department is bordered north by Burkina-Faso and the Alibori de- partment, west by Togo, east by the Borgou and Alibori departments, and south by the Donga department. Atacora, covering an area of 20,499 km² (INSAE-Bénin, 2016), is divided into nine districts: Boukoumbé, Cobly, Kérou, Kouandé, Matéri, Natitingou - which is the administrative centre-Pehunko, Tanguiéta, and Toucountouna (Figure 1).

The topography of the Atacora is marked by the eponymous mountain range that divides the territory of the department along a North-North-East/South-SouthWest axis (Figure 2). This mountain range is the western outer part of the $1,000 \mathrm{~km}$ long Dahomeyide orogenic belt, which extends from south-eastern Ghana to southern Mali. Located on the Pharusian suture, it is the result of a tectonic thrust due to the collision between the West African craton and the Benino-Nigerian craton during the Late Precambrian (between 610 and 580 million years ago; Guillot et al., 2019). For the purposes of description, the topography of the Atacora can be divided into four topographical zones: the Gourma Plain, the Mekou Plain, the High Atacora Plain, and the Atacora plateaus. At an altitude below $250 \mathrm{~m}$, the Gourma Plain extends to the west of the Atacora range, sloping gently down to the Pendjari. At a higher altitude, between $250 \mathrm{~m}$ and $450 \mathrm{~m}$, the Mekrou Plain extends to the east of the Atacora. At the same altitude, the High Plain cuts the Atacora mountain range in two. And last, above $450 \mathrm{~m}$ altitude and up to $650 \mathrm{~m}$, the Atacora plateaus dominate the region.

Several rivers flow across the Atacora, the main ones being the Pendjari, the Mekrou, the Koumagou, the Keran,

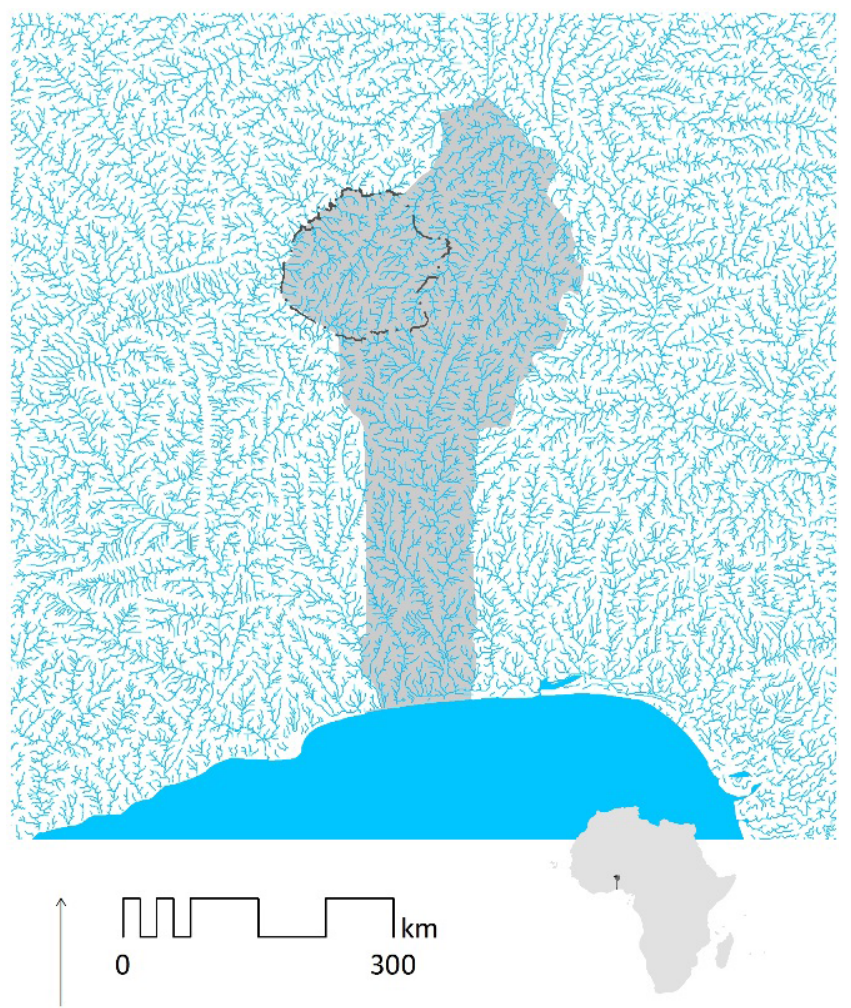

Figure 1. Benin and Atacora: Waterflows. Source: Authors. 



Figure 2. Topographic map of the Atacora. Source: Authors (with IGN data, 2019).

and the Magou (Figure 3). The Pendjari, which has its source in the high plain of the Atacora, flows through the town of Toukoutouna, joins the Gourma Plain, and flows into the Oti (tributary of the Volta river). The Mekrou rises in the east of the Atacora mountains and flows into the Niger River. The Koumagou River rises in the high plateaus of the Atacora, runs through the town of Boukoumbé, flowing into the Pendjari River in Togo. The Kéran River also rises in the Atacora highlands, runs through the town of Natitingou, and flows into the Pendjari River in Togo. Last, the Magou River draws its source in the Pendjari Plain, near Cobli, and flows further north into the Pendjari.
It is fed by several rivers from the Atacora chain, such as the Mounhoun, flowing through Tanguiéta.

\subsection{Culture}

According to the latest census of 2013, the Atakora department has a population of 772,262 inhabitants, divided into three distinct ethnic groups: the Somba; the Bariba, and the Fula (INSAE-Bénin, 2016). The Somba population (59\%) occupies the Atacora mountains and the Gourma Plain, covered by the districts of Boukoumbé, Cobly, Matéri, Natitingou, Pehunko, 


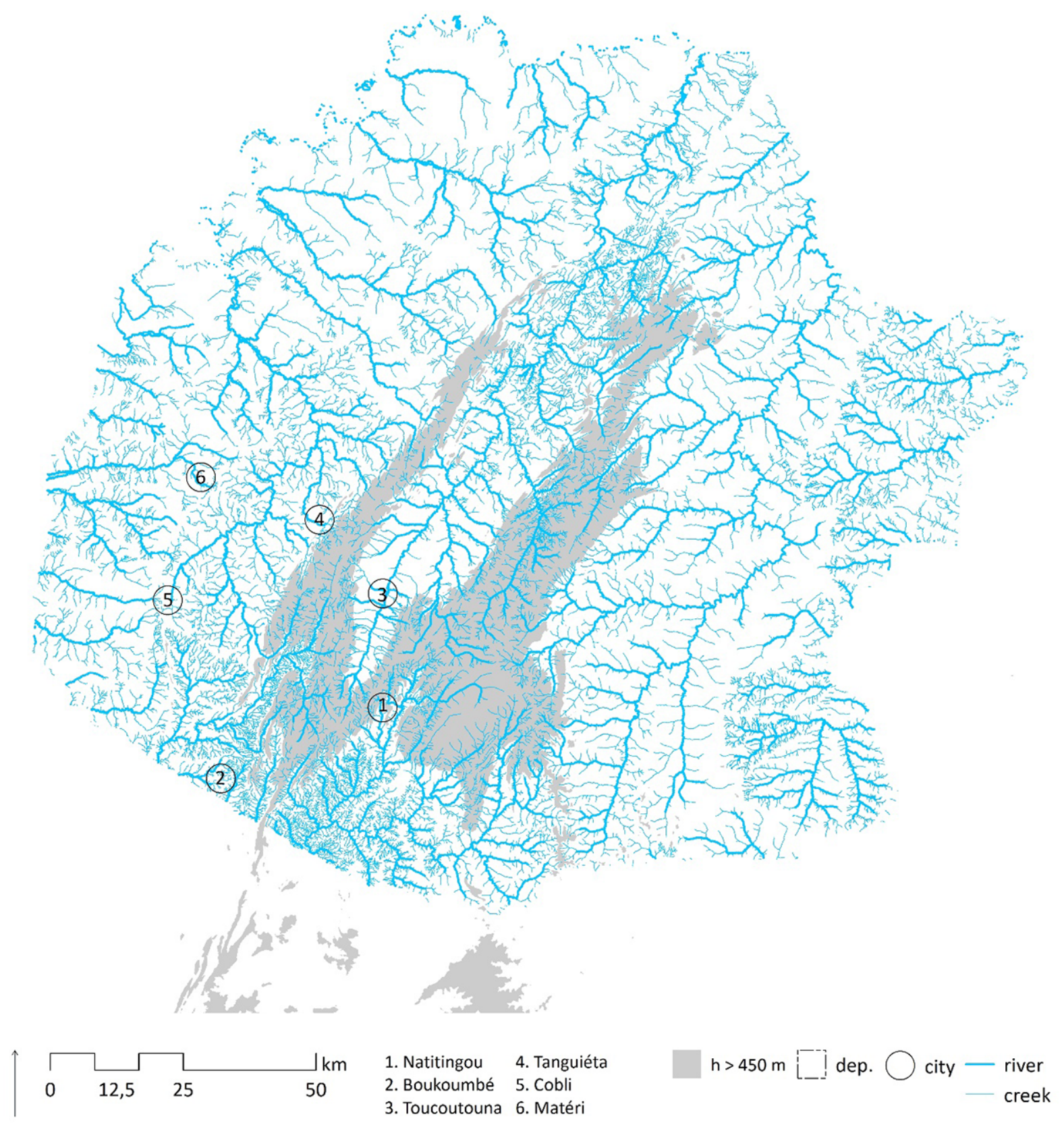

Figure 3. Hydrographic map of the Atacora. Source: Authors (with IGN data, 2019).

Tanguiéta, and Toucountouna. It includes several ethnic groups: Bétammaribé (including Bétammaribé, Béssoribé, and Bétchabé), Berba, Niendé, Natimba, Tayaba, and Waaba. The Bariba, for their part, are attached to the eastern part of the Atacora, covered by the districts of Kérou, Kouandé, and Péhunko. The Fula or Peulhs are nomadic pastoralists who set up their camps following the opportunities of transhumance.

The Somba population lives off rainfed nonmechanical agriculture on burnt land, and soil is mostly fertilised through fallowing. The available agricultural land is regularly redistributed according to the needs of the village members. The variation in soil and climate allows, from East to West, the cultivation of tubers and root crops (yam, cassava, and sweet potato), cereals (millet, maize, fonio, and sorghum) and legumes (beans and voandzou). Hunting is also quite common and takes place during the dry season from November to May.

The most recognisable elements of the traditional Somba habitat are the 'multi-storey dwellings' known as Tata Somba. Just as the term 'Somba' refers to a group of related ethnic groups, the term 'Tata Somba,' used here for its all-encompassing nature, refers without distinction to all the traditional dwellings of the Somba group. In ditammari, the language of the Betammaribé, the multi-storey dwelling is called Takyenta (plural: Sykien). The Tamberma of Togo call their dwelling Tékyenté (Blier, 1994; Padenou \& Pastor-Barrué, 2006). Built of mud, the 
Tata Somba is composed of several circular huts (approximately 2 meters in diameter) with conical roofs covered in straw. These huts are arranged in a circle and are connected to each other by curved walls (Figure 4). The first floor is made up of one or more terraces of rammed earth, supported by wooden posts and beams. The main terrace gives access to the rooms and attics on the first floor. The groundbreaking works of Maurice and Mercier revealed the existence of typological differences between the Tata of the different Somba subgroups. It is thus possible to distinguish the Tata of Otammari, Osori, Otiao, Berba, Tayaba, Niendé, and Waaba types. In addition to these different types that can be described as 'classical,' there is a 'hybrid' type of Tata Somba, which appeared in the region at the turn of the year 2000 (Padenou \& Pastor-Barrué, 2006, p. 273). It is mainly characterized by the absence of the terrace and the addition of rectangular huts covered with tin roof.

\section{Issues}

\subsection{Approaches}

The studies devoted to the traditional habitat of the Atacora have mainly covered stylistic and symbolic aspects. The first studies focused on classifying and assigning the different types of Tatas to one of the socio-cultural groups that make up the Somba people-Bétammaribé (Bétammaribé, Béssoribé, Bétchabé), Berba, Niendé, Natimba, Tayaba, and Waaba (Maurice, 1957; Mercier, 1954b). The second studies highlighted the symbolism of the traditional habitat, the division between right and left corresponding to the opposition between men and women, the division between the ground floor and the first floor, and the opposition between life and death. Considering that "the house, in fact, can be studied on its own" or that "among all the components of the Tamberma space, the Takyenta as a building, is by far the most important and also the most interesting element to analyse" (Padenou \& PastorBarrué, 2006), all these studies focus mainly on the Tata as such. As a result, most of the studies dedicated to the Somba habitat are limited to a typological or taxonomic approach of the Tata. Qualitatively, they identify the characteristic features of the structures (curvature of the walls, heights of the turrets, slope of the terrace, etc.) and define types (Mercier, 1954b) or 'models' (Padenou \& Pastor-Barrué, 2006) to which the documented structures are supposed to correspond. On the contrary, all of the studies insist on the fact that the traditional habitat is dispersed without trying to understand its implantation principles: "The Tamberma habitat is a dispersed habitat. The houses are generally a hundred meters apart" (Padenou \& Pastor-Barrué, 2006, p. 97).

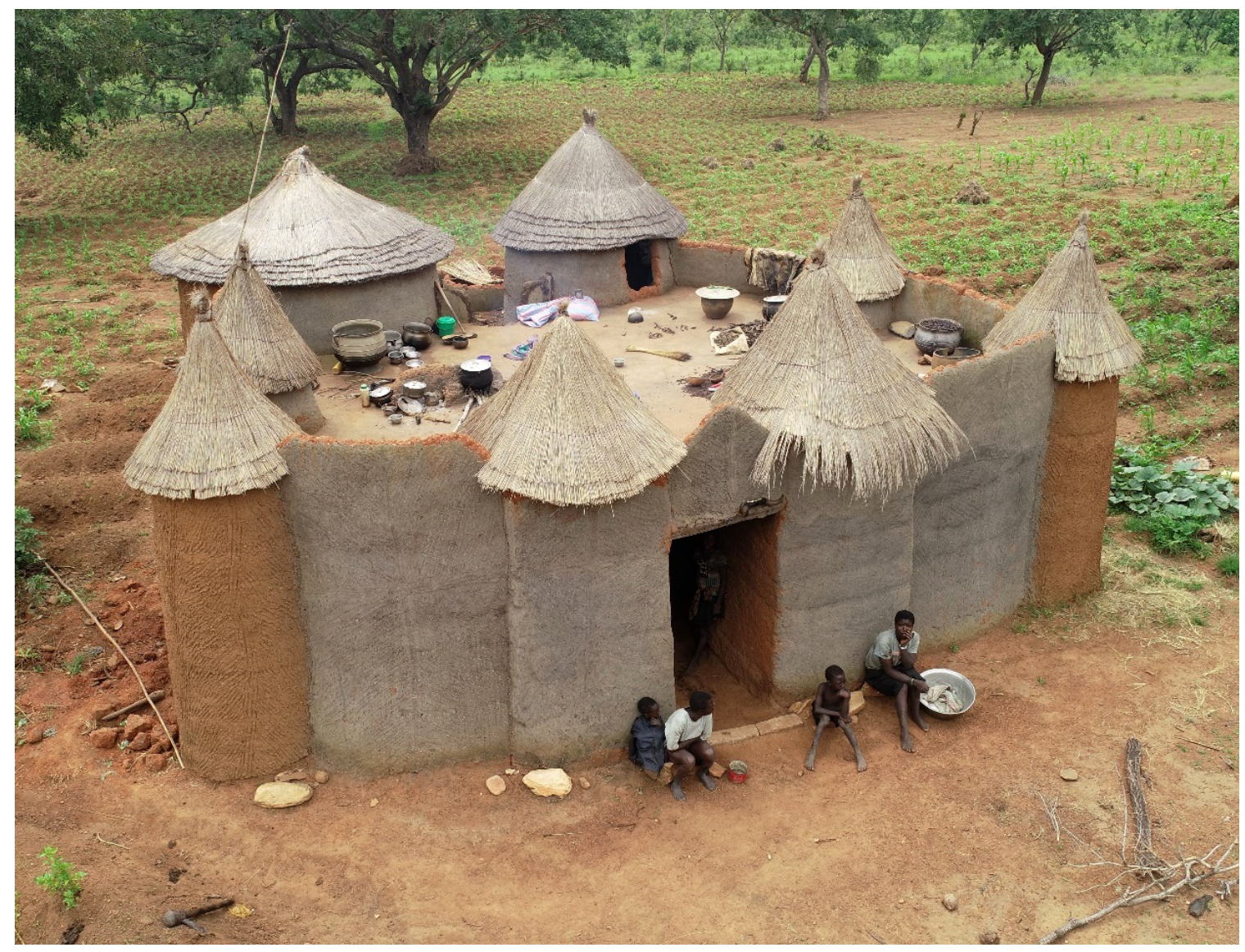

Figure 4. Photo of Tata Somba in Kouaba. Source: Authors. 
The study presented in this article adopts, first, a 'generative' (Pleitinx, 2019) or syntactic approach, complementary to the taxonomic approach. This means that the Tata is not considered as a model with a set of features subject to marginal variations, but as an entity made up of elementary units on the one hand, and as a part of larger groups, on the other. In a primary approach, these groups are, first, the domestic domain, which includes the Tata, but also the courtyard, the apatam (straw huts), the adjoining agricultural plots, etc.; second, the village, which includes the various family domains, paths, water points, etc.; and finally, the territory, which includes the villages, the roads, and the geographical lineaments of the Atacora. From this perspective, the aim is to understand, at each one of the three scales considered, the principles that rule the association of Somba habitat units, principles that constitute what could be called the "syntax of Somba architecture" (Pleitinx \& Noukpakou, 2019) and that are at the source of the formation of the 'Somba landscape.' Adopting a generative approach calls for questioning the dispersal of Somba habitat. If it is accepted as a working hypothesis that the Tatas Somba are elements of a whole, their dispersal should be seen as a consequence of the principles of the formation of this whole, rather than as a lack of consistency.

The Somba modes of production, slash-and-burn agriculture, and earthen architecture are ephemeral. Without regular maintenance, fields and tracks disappear under weeds, and buildings quickly fall into ruin, eroded by rain and wind. No visible or tangible vestiges of the ancient productions remain. According to the information collected during the inventory of the Tata Somba carried out in the districts of Boukoumbe and Natitingou on the initiative of the French Institute of Cotonou, the average age of the Tata is 54 years, while the oldest Tata is said to be 140 years old (results obtained from a sample of 1,528 individuals). Archaeological prospecting campaigns have brought to light many sites that show evidence of an ancient occupation of the Atacora territory. These are mainly caves and rock shelters, whose occupation dates back to the prehistoric period: archeometallurgical sites, ruins of ancient villages, and low mounds, some of which have been dated from the 7th to the 15 th century $A D$ and may have been occupied by populations from which the current populations are descendants ( $N^{\prime}$ Dah, 2009). Furthermore, the agricultural practices and construction of the Tata Somba do not require any heavy or invasive superstructure or infrastructure. While the Somba people's agricultural production methods may have played a part in the partial deforestation of the Atacora, they have neither transformed its topography nor changed its watercourses. The Somba landscape can be compared to a palimpsest whose red chalk text has been erased many times with the fingertips, leaving the fibers of the parchment intact.

Second, this study adopts a territory-as-palimpsest approach, questioning the dispersal of Somba habitat throughout history. Following Corboz $(1983,1993)$, this approach aims to reveal the permanency, the persistency and also the disappearance of landscape elements. In the particular case of the Somba landscape, it implies to also take into account the perpetuation of settling practices that bear witness to the existence of something like a 'common mental palimpsest.'

\subsection{Hypotheses}

The ephemeral and light nature of agricultural production and traditional housing does not exclude the persistence of their settlements nor the perpetuation of some settling practices. The study is therefore based on the working hypothesis that there is an order, a logic underlying the dispersal of Somba habitat. In this case, this article focuses on testing two hypotheses that are mutually non-exclusive.

The Sikyen of Togo settle at a distance from each other, saving a surrounding area, where fields are "cultivated by women" (Padenou \& Pastor-Barrué, 2006, p. 110). However, for family reasons, they settle close to one another, "an arrow range away" (Cornevin, 1973). This principle of settlement is a factor both in the concentration of the Tatas and in the settlement of villages in a particular spot within the territory of some Tatas. If the Tamberma settlement pattern is the same among the Somba in Benin, it should be possible to observe, despite their apparent dispersion (Cornevin, 1973, p. 23), that they maintain a relatively constant spacing between two Tatas Somba. In addition, if these settlement principles are permanent, it should be possible to verify that the newer hybrid Tatas maintain the same distance to the neighbour. It should also be possible to observe a proximity between the Tatas and the various archaeological sites inventoried by archaeologists, especially the anthropic mounds ( 7 th to 15 th century).

The Tatas Somba are built in raw earth and are used, among other purposes, to store harvests. In this regard, they have an ambivalent relationship with watercourses. On one hand, water is a necessity for the construction of the Tata, required for mixing the mud, and for agricultural activity, as it needs a sufficiently wet soil. On the other hand, the rivers are a threat to the constructions, degraded by erosion, and to the crops, endangered by floods. It can be assumed that choosing a site for the construction of a Tata is the result of a balance between the need and the threat represented by water. If this is the case, it should be possible to observe a recurrent positioning of Tata in relation to watercourses. If this relationship to the watercourse is a permanent principle, there should also be a link between, first, the hybrid Tatas Somba and the watercourses and, second, between the most recent archaeological sites and the watercourses. Without being the sole or main determinant, the hydrographic network of the Atacora should thus constitute a matrix for the geographical location of the Somba habitat. 


\section{Method}

\subsection{Data}

Both hypotheses are here tested by a statistical analysis conducted using the QGIS program. The analysis uses several data sets.

First, it uses the 1:50,000 scale maps produced by the IGN of Benin and accessible on its Geoportal since 2019 (www.geobenin.bj). It mainly uses data relating to watercourses. Drawn accurately and exhaustively, they are classified, namely, by type-river or stream-and by regime-permanent or temporary.

It then uses the geolocated inventory of traditional raw earth habitats carried out by the author and based on satellite imagery from 2019 as part of the HTC-Atacora project. Funded by the Walloon Air and Climate Agency (AwAC) and led by UCLouvain in partnership with Eco-Bénin and Yves Baudot, the HTC-Atacora project aims to preserve raw earth habitats and to promote the construction of raw earth habitats resistant to climate change and low timber and firewood consuming.

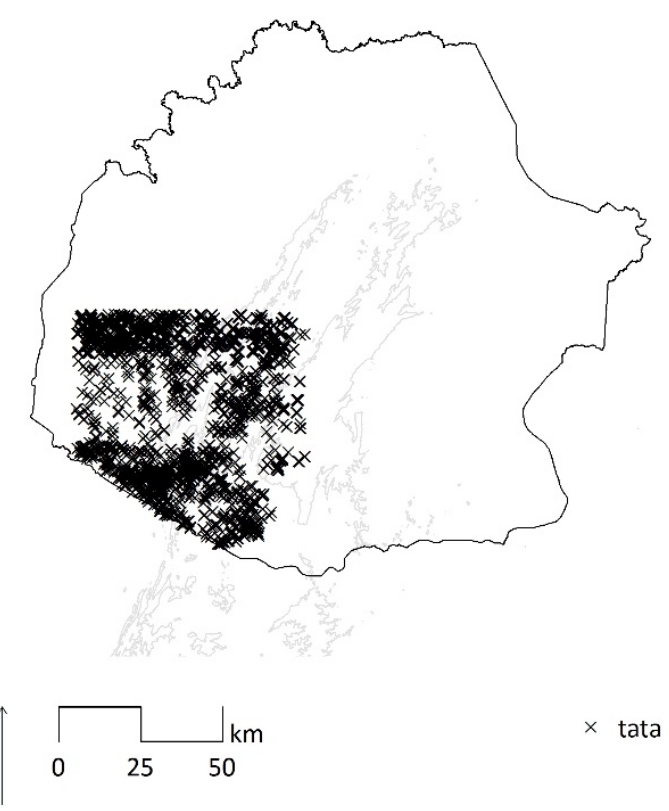

Figure 5. Tata Somba inventory. Source: Authors.
This inventory covers a limited portion of the territory covering 4,507 km (Figure 5) and allows the identification of 3,546 Tatas Somba, with a distinction between two types. The first type of Tata Somba corresponds to the multi-storey housing of which the variations were described by Maurice (1957) and Mercier (1954a) and represents almost $60 \%$ of the Tatas inventoried. The second type is a hybrid, maintaining the configuration of the traditional Tata Somba; it does not have a storey and occasionally includes blocks with a rectangular floor plan, and represents $40 \%$ of the inventoried Tatas.

Finally, the study uses the list of archaeological sites in the Atacora taken from the appendices of Didier N'Dah's (2009) thesis, defended in 2009 (Table 1). Of the 173 sites listed in our study area, 132 are located using geographical coordinates. These sites are of several types: caves, rock shelters, open-air sites, metallurgical sites, and anthropic mounds spread across the territory of Atacora (Figure 6).

Of all the archaeological sites, the study focuses mainly on the more recent anthropogenic mounds, which appear to correspond to a habitat.

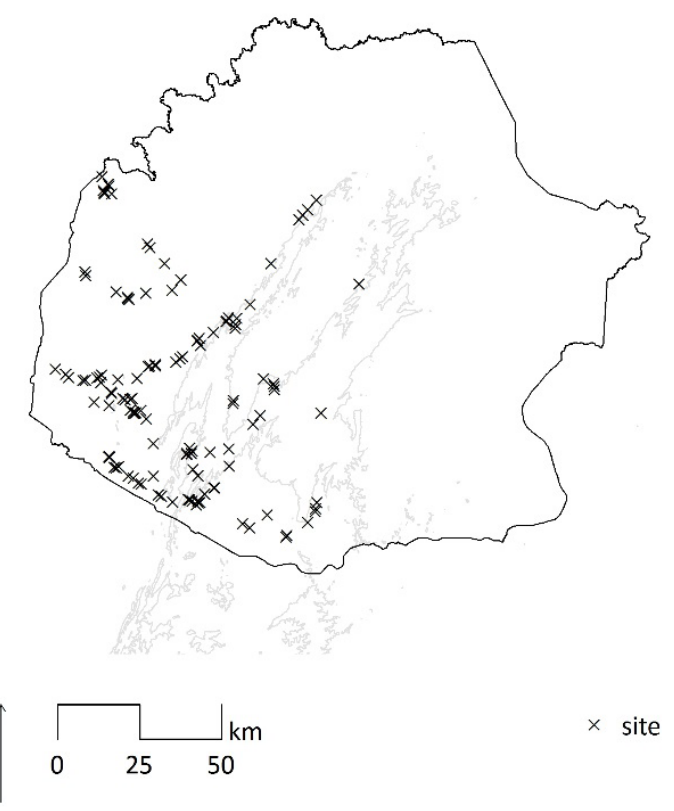

Figure 6. Archaeological sites. Source: N’Dah (2009).

Table 1. Number and types of archaeological sites.

\begin{tabular}{lccc}
\hline Types & Listed & Geolocated & Non-geolocated \\
\hline Rock shelters & 10 & 10 & 0 \\
Anthropic mounds & 83 & 74 & 9 \\
Caves & 7 & 5 & 2 \\
Open-air sites & 64 & 36 & 28 \\
Metallurgical sites & 9 & 7 & 2 \\
Total & 173 & 132 & 41 \\
\hline
\end{tabular}

Source: N'Dah (2009). 


\subsection{Statistics}

The two hypotheses stated above are tested through a statistical analysis of the distances between the given hydrographic, architectural, and archaeological elements.

To test the first hypothesis whereby Tatas settle close to each other, or even in the location of former Tatas, the analysis focuses on the shortest distance between two inventoried Tatas. To test the historical depth of this hypothesis, the results between classical Tatas and hybrid Tatas are compared. The analysis is then extended to the shortest distance between Tatas and anthropic mounds. To test the second hypothesis whereby Tatas are settled in a way that ensures their access to water while protecting themselves from threats, the distance between a Tata and the nearest watercourse is first examined. To further investigate this hypothesis in time, we are also interested in the behavior of hybrid Tatas Somba and the distance between an anthropic mound and the nearest watercourse. In both cases the statistical results are interpreted by mapping the notable locations on the satellite images.

In Atacora, the topography and density of the hydraulic network vary considerably from one geographical point to another. Anticipating the fact that these variations may have an impact on the studied distances, the Atacora territory has therefore been divided into five study areas (Figure 7). Zone 1 corresponds to the plain irrigated by the Keran and its tributaries, where the majority of the Tatas of the Besoribé type are found. Zone 2 corresponds to the plain drained by the Koumagou River and its tributaries, where Tatas of the Bechabé type are found. Zone 3 corresponds to the high plain of the Atacora, where the Pendjari River takes its source and where a part of Tata Somba of the Betammaribé and

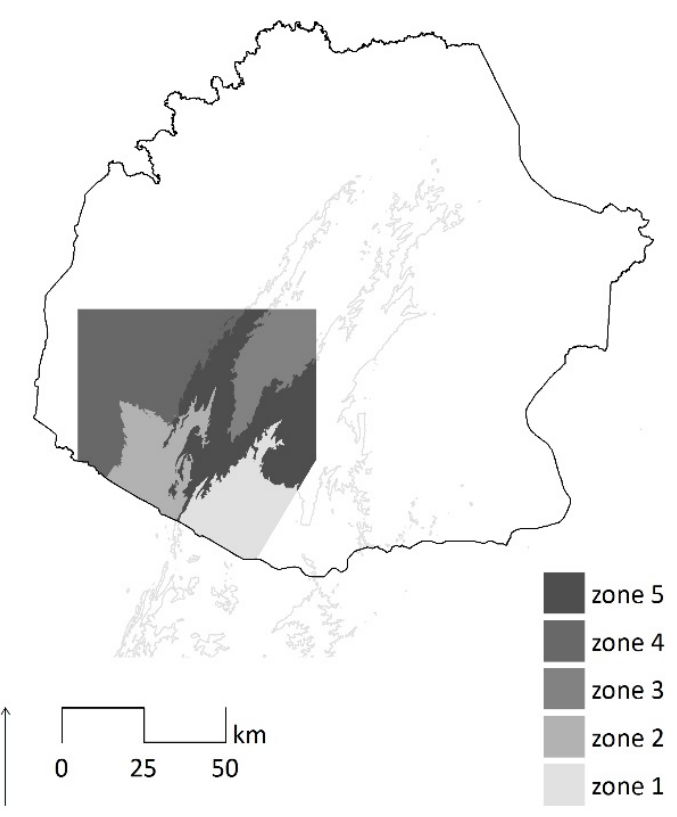

Figure 7. Study zones. Source: Authors.
Berba type are found. Zone 4 extends over the plain of the Gourma, where the Magou and its tributaries flow, and where the Tatas of Berba type are gathered. Zone 5, finally, corresponds to the Atacora plateaus, where the majority of Tatas Somba of the Betammaribé type are found. Zones 1, 2, and 4 cover the plains at the foothills of the Atacora, while Zones 3 and 5 cover the mountain range. Receiving the waters of the Keran and Koumagou rivers that flow down from the mountains, Zones 1 and 2 have a much higher density of streams than Zones 3 and 4.

\section{Analysis}

QGIS software allows to measure the shortest distance separating two points as well as between a point and a line. It provides statistics and histograms that allow to appreciate the position and the dispersion of the measurements.

\subsection{Spacing}

The statistics (see Table 1 in the Supplementary File) for the shortest distance separating two Tatas Somba reveal a wide range of spacing in all areas, from $11 \mathrm{~m}$ to $4309 \mathrm{~m}$. In addition, for all areas, an important standard deviation is observed, indicating a wide dispersion of measurements. However, with the exception of Zone 2, this dispersion is very asymmetrical, as revealed by the large differences between the average and median values, but also by the fact that the average is greater than Q3 in Zones 3, 4, and 5. In such cases of asymmetry, the values Q1, median, Q3, and mode are statistically more indicative than the average and standard deviation. In terms of quartiles, there is a strong difference between Zones 1 and 2 and the other three zones with homogeneous results. For these three zones, in particular, the interquartile range is very narrow compared to the standard deviation. The two zones covering the Atacora mountain range, plain (Zone 3 ) and plateau (Zone 5), obtain almost identical results. But in all five zones, the mode, i.e., the most observed value, ranges between $50 \mathrm{~m}$ and $75 \mathrm{~m}$ (Figure 8).

These results show that the shortest distance between two Tatas is subject to great variations. However, Tatas tend to settle close to one another. These results show a tendency to maintain the modal distance (50-75 meters) between two Tatas. This confirms the hypothesis of 'dependency on the predecessor' that suggests a relatively fixed settlement pattern (Figure 9).

The comparison of modal distances to nearest neighbours for type 1 Tata and type 2 Tata shows a clear convergence. This suggests that, in spite of the changes in the type, the syntactic rule of distances remains unchanged.

Generally speaking, the averages and medians of the shortest distances calculated between an archaeological site and a Tata are two to three times greater than the 


\section{DCOGITATIO}

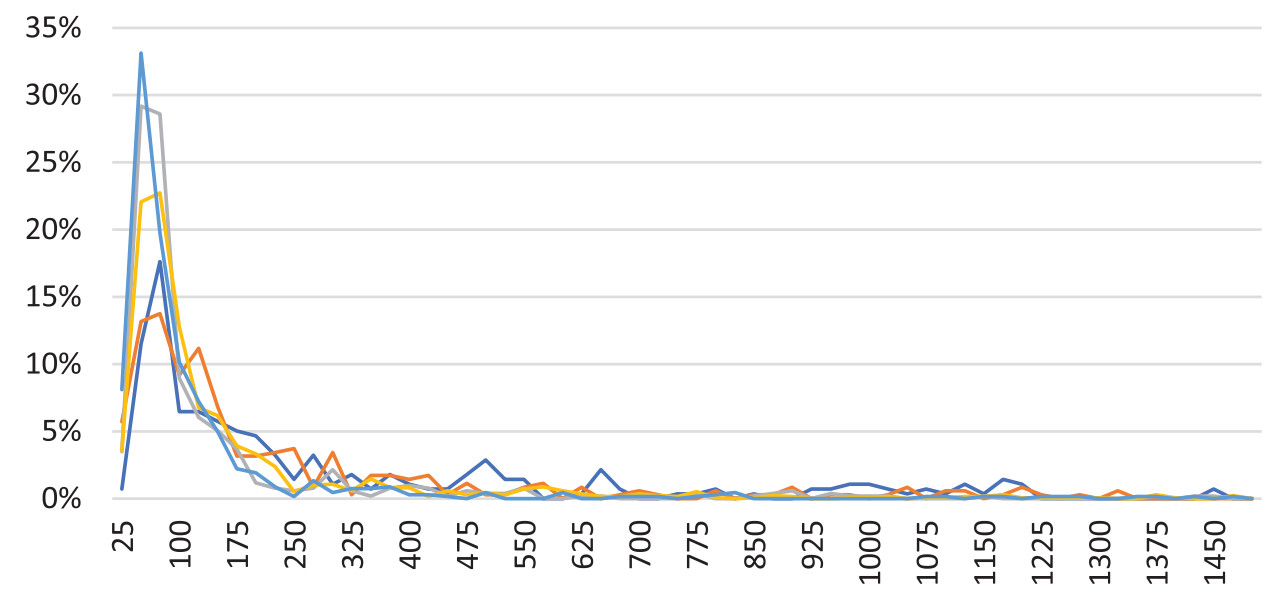

Figure 8. Histogram of shortest distances between two Tatas (Class width: $25 \mathrm{~m}$ ). Source: Authors.
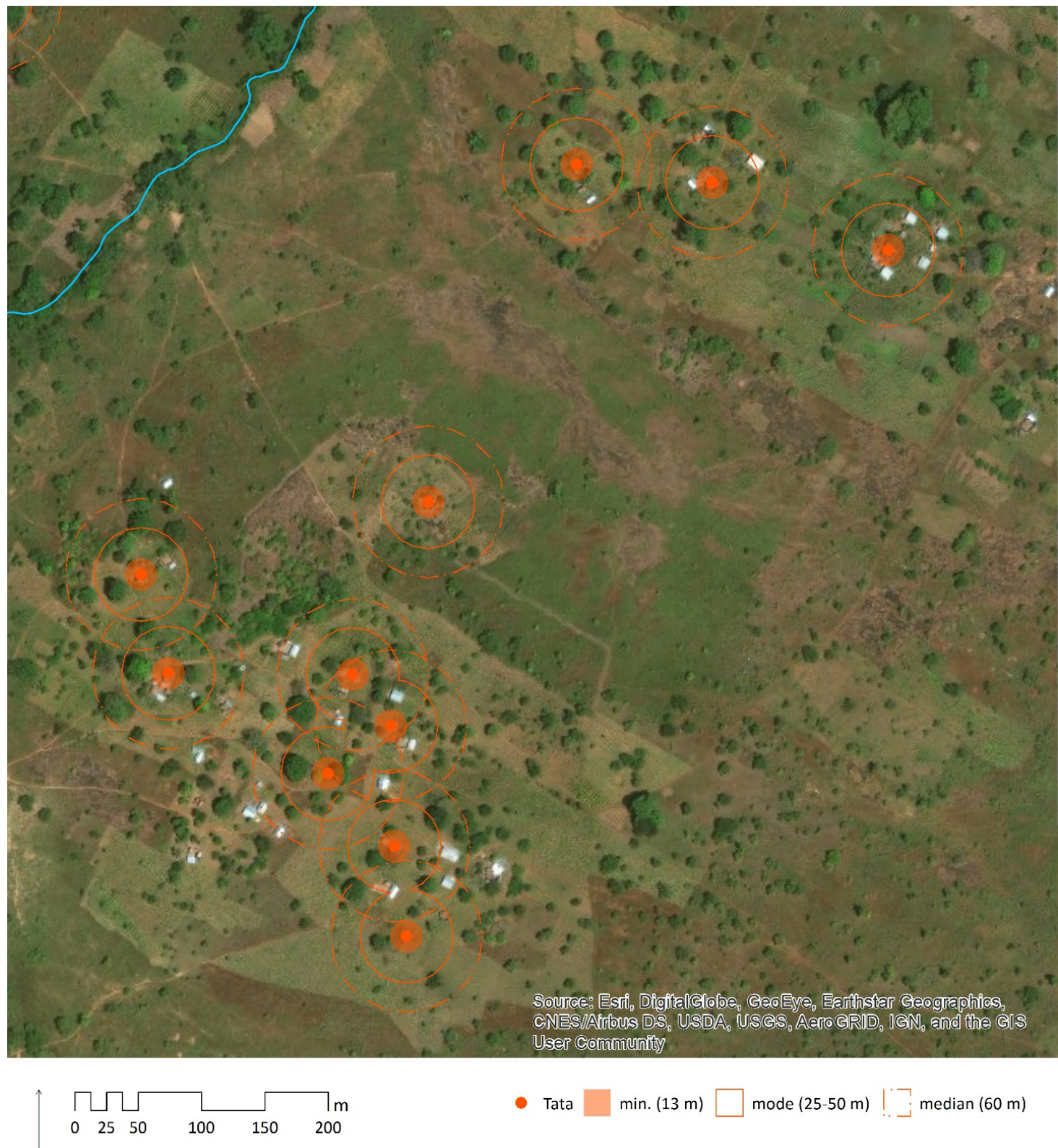

- Tata $\min .(13 \mathrm{~m}) \square \operatorname{mode}(25-50 \mathrm{~m}) \mid \cdot \operatorname{median}(60 \mathrm{~m})$

Figure 9. Analysis of shortest distances between two Tatas, Kouaba village (Zone 5). Source: Authors. 
averages and medians of the shortest distances between two Tatas Somba (see Table 2 in the Supplementary File). A finer analysis of the shortest distance between an anthropic mound and a Tata, measured in each of the zones, does not improve the score (the analysis of the distances between the archaeological sites and the Tatas is limited to the inventoried area of the Tatas Somba). The statistics do not allow to establish a connection between the existing traditional Tatas Somba and the past settlements attested by the archaeological sites, and thus conclude that these sites have remained the center of settlements in spite of their disappearance.

\subsection{Distancing}

In order to verify that the observed distribution is not a simple reflection of the hydrological configuration, it is compared, for each zone, to the distribution of the same number of people randomly spread across the territory. The statistical values (minimum, Q1, mode, and median) obtained for this sample are significantly different from the observed values, which leads to the conclusion that the Tatas Somba are not randomly scattered over the territory (see Table 3 in the Supplementary File).

Like the distances between Tatas Somba, the distributions of distances between Tatas and rivers calculated for each area are asymmetric (asymmetry coefficient $>0$ ), which reduces the informative value of the average and standard deviation. Once again, the position values: minimum, median, and mode are taken into account, as they are the most informative in the case of asymmetry (Figure 10). Considering these values, it appears that in the plain areas the minimum distance to the axis of the rivers is more or less $25 \mathrm{~m}$, while in Zone 5, corresponding to the plateaus, it is $40 \mathrm{~m}$. It also appears that, compared to the distance between Tatas (more or less $75 \mathrm{~m}$ ), the Tatas generally settle close to the watercourses, with an average of observed modes of $185 \mathrm{~m}$ and an average of observed medians of $295 \mathrm{~m}$. It also appears that the median and modal distances vary from one area to an- other. However, the results make it possible to divide the five zones into three coherent groups on a hydrographic level. In Zones 3 and 5, corresponding to the high plain and the Atacora plateaus, the median distance is overall of more or less $140 \mathrm{~m}$. In Zones 1 and 2, corresponding to the Keran and Koumagou plains, the median distance is more or less $190 \mathrm{~m}$. In Zone 4, corresponding to the Gourma plain, the median distance is $403 \mathrm{~m}$ (Figure 11).

In general, the distances vary according to the slope of the land. The correlation coefficient between the variables 'slope of the terrain' and 'distance between a Tata and the closest river,' calculated for all the Tatas, is -0.25 . Calculated for Zone 5 , which has the highest average slope, the correlation coefficient is -0.29 . Both coefficients are negative, indicating a trend away when the slope decreases, as expected. However, these two coefficients are relatively close to 0 , indicating a weak linear correlation between slope and distance to the stream. This is because the slopes in question are relatively low and the distances are relatively short. These favorable conditions offer great leeway in choosing a place to settle.

The comparison of modal distances to nearest watercourse for type 1 Tata and type 2 Tata shows again an obvious convergence, which suggests that, despite the changes in the type, the syntactic rule of distances to watercourses also remains unchanged.

In order to test the historical depth of the hypothesis of proximity between the Tatas and water, the distance between an anthropic mound and the nearest watercourse was also calculated. Comparing the tables 'Tata-hydro' and 'mounds-hydro' (see Table 4 in the Supplementary File), it can be seen that, regardless of the area, the range of distances between a mound and the nearest watercourse is smaller, and sometimes significantly smaller (361 versus 1,247 meters). Overall, the mounds are closer to watercourses than the Tatas. There is a variation in average and median values between areas. They are smaller in Zones 1 and 2 than in Zones 3, 4 and 5 . We see the same proportion in the distances

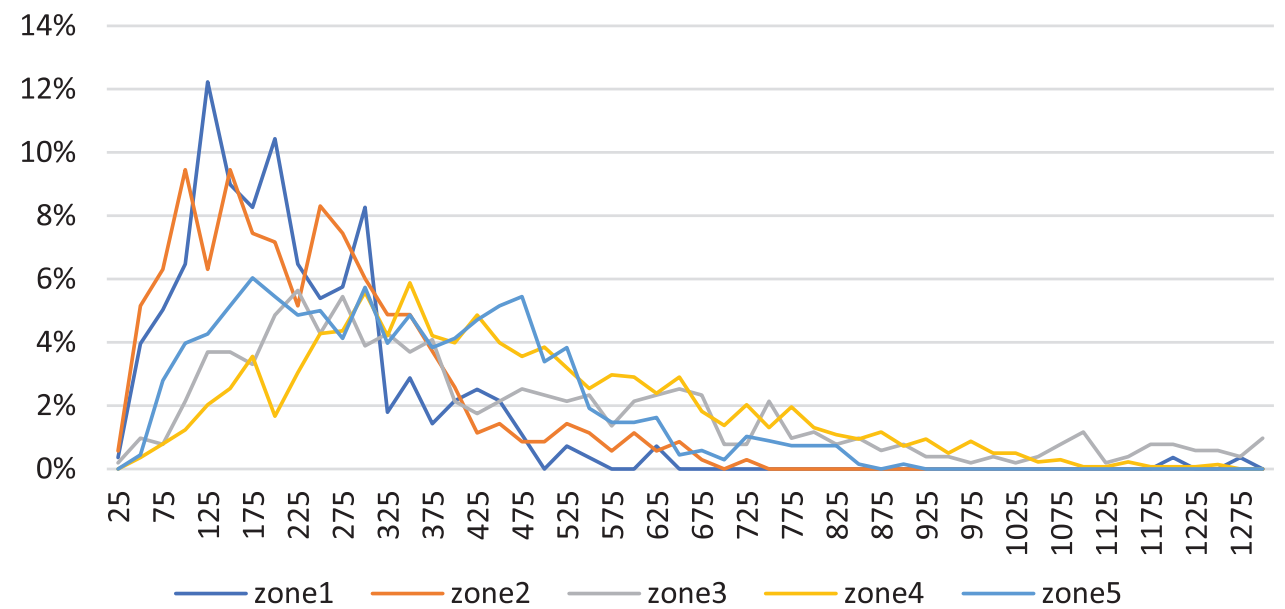

Figure 10. Histogram of shortest distances between a Tata and a watercourse (Class width: 25 m). Source: Authors. 



- Tata $\min .(27 \mathrm{~m}) \square \operatorname{mode}(325-350 \mathrm{~m}) ! \cdot \neg \operatorname{median}(409 \mathrm{~m})$

Figure 11. Analysis of shortest distances between a Tata and a watercourse, alongside the Kouloumbouanga river (Zone 4). Source: Authors.

between the Tatas and the watercourses. The values obtained in Zone 4, which has the largest number of mounds, are the closest to values found for the Tatas in this zone. The minimum distance of more or less $25 \mathrm{~m}$ is respected. The average and median distances are very close. The locations of the anthropic mounds correspond to those of the Tatas, as the differences, ranging from 3 to $5 \%$, remain quite small.

\section{Conclusion}

By studying the Tatas Somba from a generative perspective and a territory-as-palimpsest approach, the research presented in this article sought to further understand the dispersal of the Tatas Somba, as it is one of the characteristic features of the Somba landscape. Two hypotheses were put forward regarding the links between the Tatas and their links to watercourses. The first of these two hypotheses was tested through an analysis of the shortest distance between two Tatas and then through an analysis of the shortest distance between an archaeological site and a Tata. As for the second hypothesis, it was tested through an analysis of the distance between a Tata and the nearest watercourse, and then through an analysis of the distance between an archaeological site and the nearest watercourse. Both analyses corroborated the hypotheses and allowed the identification of recurring distances. 
In spite of great variations, it can be observed that Tatas settle close to one another, at a modal distance ranging from $50 \mathrm{~m}$ to $75 \mathrm{~m}$. Frequently observed, especially in the areas around to the Atacora Mountains (high plain and plateau), this modal distance corresponds to the distance between Tatas belonging to the same village, and thus gives a more accurate measure of the famous 'arrow range' of Cornevin (1973). Despite wide variations, once again, it can be observed that the Tatas also settle near watercourses, at a modal distance that varies according to the areas studied, ranging from $75 \mathrm{~m}$ to $325 \mathrm{~m}$. In all study areas, a $25 \mathrm{~m}$ wide buffer zone is maintained on both sides of the axis of watercourses.

The settlement of the Tatas Somba is not determined by geometrical compositions, landmarks, or infrastructures. The Tatas Somba are dispersed by the effect of centrifugal factors, e.g., family need for agricultural land and threat of water, but this dispersion is tempered by factors with centripetal effects-cooperation and need for water. The combination of these factors leads to the definition of equilibrium points or lines around which the Somba people establish their dwellings.

The hybrid Tatas that appeared around the year 2000, despite their typological modification, maintain the same distances as classic Tatas between neighbours. The state of abandonment and ruin of the archaeological sites discovered in Atacora attest to the ephemeral nature of the traditional habitat in Atacora. They are located outside and at a distance from the settlements. Following the same logic as the classic ones, the hybrid Tatas are settled at a modal distance ranging from $75 \mathrm{~m}$ to $325 \mathrm{~m}$. Overall, the archaeological sites are located closer to the watercourses than the Tatas Somba. The anthropic mounds are also located close to watercourses, closer than are the Tatas to watercourses.

The Somba landscape is a moving palimpsest. Due to the ephemeral and fragile agricultural and architectural modes of production, the elements of the Somba landscape (Tatas, fields, tracks, etc.) appear to be impermanent and even nonpersistent. Nevertheless, this study suggests the perpetuation of the same settling habits, which shows the existence of a bolder mental palimpsest than the material one. Furthermore, it shows that proximity to water is an important parameter in the settlement of the habitat in Atacora, revealing the hydraulic network as the permanent underwriting of the Somba palimpsest.

This article calls for developments in the field of research and suggests some reflections on heritage preservation.

The present study is far from having exhausted the understanding of the Somba landscape. Indeed, the analysis should be refined by testing alternative social and environmental hypotheses. On one hand, it would be appropriate to study the impact of more specific social relationships, such as belonging to clans or kinship ties, on the settlement of the Tatas Somba in the same village. On the other hand, it would also be necessary to study the impact of environmental factors such as pedology or land exposure (Hahn-Hadjali, Braun-Yao, Franke-Scharf, \& Fritscher, 2000).

Furthermore, the analysis could be extended by finely describing the agricultural and non-agricultural uses of the spaces separating neighboring Tatas, as well as the spaces between Tatas and watercourses.

The balances that structure the Somba landscape are unstable. Nowadays, these balances are threatened both by social changes, such as rural exodus and monetarisation of trades, and by climate change, which is speeding up the process of sahelisation affecting the Atacora (Agbanou, 2018). If not protected, it is doomed to disappear. However, the protection of the heritage of the Atacora should not only aim to maintain the current buildings, but rather to preserve and empower the Somba's agricultural way of life and to protect their living environment.

The Somba people live alongside the rivers. Despite their dispersion, they occupy and share the watersheds of tributaries of the Pendjari River flowing further south into the Volta River. Measures to preserve the Somba landscape cannot be decided and applied within the limits imposed by the administrative division of the Atacora, but should be concerted and implemented within the unitary framework of the watersheds, so as to take into account the river solidarity that is de facto essential for all the inhabitants of the Atacora (Garané, 2009).

\section{Acknowledgments}

This research is supported by a PhD Scholarship from the UCLouvain's International Action Committee (CAI). The geolocated inventory of Tatas was conducted, and photos were taken, by Fabrice Noukpakou, Jules Landjohou under the supervision of Yves Baudot, expert geographer, as part of the project HTC-ATACORA, funded by the AWAC (Walloon Air and Climate Agency) and UCLouvain. Some of the data on Tata Somba come from the detailed inventory conducted by the French Institute of Cotonou, Benin.

\section{Conflict of Interests}

The authors declare no conflict of interests.

\section{Supplementary Material}

Supplementary material for this article is available online in the format provided by the authors (unedited).

\section{References}

Agbanou, B. T. (2018). Dynamique de l'occupation du sol dans le secteur Natitingou-Boukombé (Nord-ouest Bénin): De l'analyse diachronique à une modélisation prospective [Land use dynamics in the NatitingouBoukombé sector (North-West Benin): From di- 
achronic analysis to prospective modelling] (Unpublished Doctoral dissertation). University of ToulouseJean Jaurès, Toulouse, France, and University of Abomey-Calavi, Benin.

Blier, S. P. (1994). The anatomy of architecture: Ontology and metaphor in Batammaliba architectural expression. Chicago, IL: University of Chicago Press.

Corboz, A. (1983). The land as palimpsest. Diogenes, 31(121), 12-34.

Corboz, A. (1993). Le dessous des cartes [The underside of the maps]. In Atlas du territoire genevois: Permanence et modifications cadastrales aux XIXe et XXe siècles [Atlas of the Geneva territory: Permanence and cadastral modifications in the 19th and 20th centuries] (pp. 4-7). Geneva: Georg.

Cornevin, R. (1973). Le Togo [Togo]. Paris: Presses Universitaires de France.

Garané, A. (2009). Le cadre juridique international du bassin de la Volta [The international legal framework of the Volta basin]. Gland: IUCN.

Guillot, S., Agbossoumondé, Y., Bascou, J., Berger, J., Duclaux, G., Hilairet, N., \& Scwartz, S. (2019). Transition from subduction to collision recorded in the PanAfrican arc complexes (Mali to Ghana). Precambrian Research, 320, 261-280.

Hahn-Hadjali, K., Braun-Yao, M., Franke-Scharf, I., \& Fritscher, N. (2000). Interdépendance du potentiel d'exploitation et la structure d'habitat dans la région de l'Atkora [Interdependence of exploitation potential and habitat structure in the Atkora region]. Berichte des Sonderforschungsbereichs, 268(14), 197-207.

INSAE-Bénin. (2016). Cahier des villages et quartiers de ville du département de l'Atacora [Book of vil- lages and city districts of the department of Atacora]. Cotonou: National Institute of Statistics and Economic Analysis.

Maurice, A.-M. (1957). Au Dahomey, les châteaux Somba [In Dahomey, the Somba castles]. Tropiques : Revues des Troupes Coloniales Françaises, 395, 59-66.

Mercier, P. (1954a). L'habitation (à étages) dans l'Atakora [The (multi-storey) dwelling in Atakora]. Cotonou: Office of Overseas Scientific and Technical Research.

Mercier, P. (1954b). L'habitation à étage dans l'Atakora [The multi-storey dwelling in Atakora]. Études $D a$ homéennes, 11, 30-79.

N'Dah, D. (2009). Sites archéologiques et peuplement de la région de l'Atakora (Nord-ouest du Bénin) [Archaeological sites and settlements in the Atakora region (North-West Benin)] (Unpublished Doctoral dissertation). University of Ouagadougou, Ouagadougou, Burkina-Faso.

Padenou, G.-H., \& Pastor-Barrué, M. (2006). Architecture, société et paysage Bétammaribé au Togo: Contribution à l'anthropologie de l'habitat [Architecture, society and landscape Bétammaribé in Togo: Contribution to habitat anthropology]. Toulouse: Presses Universitaires du Mirail.

Pleitinx, R. (2019). Théorie du fait architectural: Pour une science de l'habitat [Theory of the architectural fact: For a science of habitat]. Louvain-la-Neuve: Presses Universitaires de Louvain.

Pleitinx, R., \& Noukpakou, F. (2019). L'adaptabilité de l'architecture otãmmari [The adaptability of Otãmmari architecture]. Paper presented at the Conference "Vivre en Ville-Vivre la Ville" ["Living in the City-Living the City"], Cotonou, Benin. Retrieved from http://hdl.handle.net/2078.1/221330

\section{About the Authors}
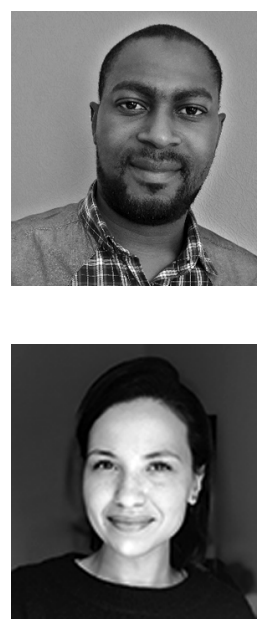

Ghita Barkouch is a graduated Architect and currently a PhD Fellow in the Faculty of Architecture, Architectural Engineering and Urban Planning of UCLouvain. Her doctoral research, assuming that architecture is a fundamentally human competence, investigates its application within immigration contexts. The research focuses on the adaptation of non-native housing methods to native housing types, by examining cases of installation and use of Moroccan living rooms in the traditional Brussels houses and of European livings in the Riads of Marrakech, Morocco.

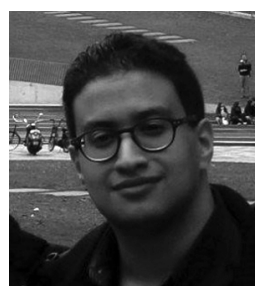

Nawri Khamallah is a young Research Assistant who graduated in Architecture from UCLouvain. He is currently a Doctoral Student in the Faculty of Architecture, Architectural Engineering and Urban Planning at UCLouvain. Affiliated with the Architecture Analysis Laboratory (AAL-LAA), his research fields are located in the fields of digital, virtual reality, digital data acquisition, and architectural visualization. His current research focuses on the relationship and impact between digital modeling tools and representations of architecture through interfaces and ergonomics. 


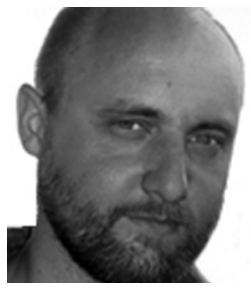

Renaud Pleitinx is a Civil Engineer Architect, has a PhD in Applied Science, and is Associate Professor at the Faculty of Architecture, Architectural Engineering and Urban Planning at UCLouvain. He teaches both theory of architecture and architectural design. His fields of research are architectural theory and research by design. Co-founder of the Architecture Analysis Laboratory (AAL-LAA), he is the author of a theory of architecture based on Jean Gagnepain's clinical anthropology. 